\title{
COMPLEX MODEL OF SOCIAL ADAPTATION OF SERVICEMEN, DISCHARGED FROM MILITARY SERVICE
}

\author{
Venelin Terziev \\ Academician of the Russian Academy of Natural History, Moscow, Russia, Prof. D.Sc. (Ec.), D.Sc. \\ (National Security), D.Sc. (Social Activities), Ph.D., National Military University, Veliko Tarnovo, \\ Bulgaria; University of Rousse, Rousse, Bulgaria, terziev@skmat.com
}

\begin{abstract}
Based on the theoretical analysis of contemporary realities and actual needs, this report presents the development of a competence model for social adaptation of released by the Bulgarian army servicemen. The focus is on knowledge and skills in terms of building competencies according to the European qualification framework. Lifelong learning is underlined as an inseparable part of the system of social adaptation considering the necessary changes in the field of education and training in Bulgaria too. Bearing in mind that those problems are not limited to the examined group under risk, main conclusions concern vocational education and training as deserving special consideration in the establishment of the social adaptation system and educational reforms in the country.
\end{abstract}

Keywords: model, social adaptation, servicemen.

\section{INTRODUCTION}

The formation of a complex model of social adaptation of the servicemen, passing in the reserve and the members of their families shall be carried out based on specific social fund. Created in the early to mid-90s of last century, this fund serves as a basis for a comprehensive reorganization and restructuring of the Bulgarian society. In particular it comes to the following specific characteristics.

Nineties of last century, accompanied by political and socio-economic changes, occurring around the world and the Bulgaria's transition to a market economy, are also the years of the carried out radical military reform in our country, the result of which is the downsizing of the military forces. The carried out measures led to the discharge of a large amount of active people from within the group of officers, sergeants, petty officers and the members of their families. This leads to growing social tension in society. Despite the actions taken by the state and the efforts of various social groups, the realization of programs for social adaptation of the discharged from military service servicemen, this group remains a risk groupin the labor market. 


\section{COMPLEX MODEL OF SOCIAL ADAPTATION OF SERVICEMEN, DISCHARGED FROM MILITARY SERVICE}

An important characteristics of the social situation in the field of the work with the discharged from military service servicemen and the members of their families is the virtually universal failure of existing social institutions in the complex solving of the problems of this process in the new conditions of life, and the inclusion of the discharged servicemen and the members of their family in active life in market conditions.

Thus, the social situation created in this area, determines another concept of the social adaptation of the servicemen, passing in the reserve and the members of their families.

In accordance with these specifics, the basic conceptual ideas of the given model have the following priorities:

First, for the first time as a basic priority is used the term „social adaptation of servicemen” instead of the earlier used term "conversion” and provision of employment to military staff. The approbation of this conceptual priority is realized within the Social Adaptation program.

The structure of the program in Bulgaria includes the following units (Table.1):

Program and operational unit, comprising a Program Director and program coordinators;

Financial department, comprising Financial Director and treasurer-accountant.

Table 1. Structure of the „Social adaptation” program

\begin{tabular}{|c|c|c|c|}
\hline \multicolumn{2}{|c|}{$\begin{array}{c}\text { Program and operational unit } \\
\text { Program director } \\
\text { Program coordinator } \\
\text { Chief coordinator of the CRTSA }\end{array}$} & \multicolumn{2}{|c|}{$\begin{array}{l}\text { Financial accounting department } \\
\text { Financial director } \\
\text { Cashier- accountant }\end{array}$} \\
\hline $\begin{array}{l}\text { CRTSA Sofia } \\
\text { Chief coordinator } \\
\text { Coordinator for } \\
\text { professional } \\
\text { orientation } \\
\text { Coordinator for } \\
\text { professional } \\
\text { orientation } \\
\text { Coordinator for } \\
\text { psychosocial } \\
\text { adaptation } \\
\text { Business consultant } \\
\text { Legal advisor } \\
\text { Administrator } \\
\text { Assistant } \\
\text { administrator }\end{array}$ & $\begin{array}{l}\text { CRTSA Plovdiv } \\
\text { Chief coordinator } \\
\text { Coordinator for } \\
\text { professional orientation } \\
\text { Coordinator for } \\
\text { professional orientation } \\
\text { Coordinator for } \\
\text { psychosocial adaptation } \\
\text { Legal advisor } \\
\text { Administrator }\end{array}$ & $\begin{array}{l}\text { CRTSA Sliven } \\
\text { Chief coordinator } \\
\text { Coordinator for } \\
\text { professional orientation } \\
\text { Coordinator for } \\
\text { professional orientation } \\
\text { Coordinator for } \\
\text { psychosocial adaptation } \\
\text { Administrator }\end{array}$ & $\begin{array}{l}\text { CRTSA Veliko } \\
\text { Taronvo } \\
\text { Chief coordinator } \\
\text { Coordinator for } \\
\text { professional } \\
\text { orientation } \\
\text { Coordinator for } \\
\text { professional } \\
\text { orientation } \\
\text { Coordinator for } \\
\text { psychosocial } \\
\text { adaptation } \\
\text { Legal advisor } \\
\text { Administrator }\end{array}$ \\
\hline & & $\begin{array}{c}\text { RIC -Stara Zagora } \\
\text { Coordinator }\end{array}$ & $\begin{array}{l}\text { RIC-Varna } \\
\text { Coordinator }\end{array}$ \\
\hline
\end{tabular}

Centers for Re-qualification and Social Adaptation (CRSA), 4 in total, were established it the towns of Sofia, Plovdiv, Sliven and Veliko Tarnovo and are led by senior regional coordinators. In these centers work coordinators on psycho-social adaptation, career guidance, business consultants, legal advisers and administrators; Regional Information Centers (RIC), while in early 2003 to the CRSA Veliko Tarnovo operate two RICs in Shumen and Varna, and to the CRSA- Sliven operates one RIC in Stara Zagora. 
The program, as presented, can be seen as a model for an integrated approach (and a complex model) to solving the problems of the discharged from military service servicemen and the members of their families. At that, the objective is not to adapt to civilian life all the discharged from Bulgarian army servicemen or to assist all the members of their families. The objective of the program is to develop and set up a mechanism for solving complex social problems of the said category of the population, creating a complex model (or several models) of organization of this process on the basis of self-support.

Second, the integrated approach is not only a comprehensive solution to the problems, relating to the adaptation of people to new conditions, but at the same time a change in the social environment. These problems are: introduction of new, more advanced technologies of „production”, staff training, organizing the social work, social-pedagogical activities. The results of the realization of such projects are: socio-economic development of the planning regions at the expense of inclusion in the process of the economically active and highly professional staff of the servicemen, passing in the reserve and the members of their families; establishment of social partnership with reducing as a result, the tension in this social group; infrastructure development of civil society, and so on.

Third, the complex nature of the proposed model and the based on it program, is determined by the sociopedagogical value orientations in its structure and content.

The starting point in creating the complex model of social adaptation of servicemen and their families lies in the very concept of „a model”. In logic and methodology of science it is an analogue of a particular fragment of the natural or social reality, a brainchild of human culture, conceptualtheoretical model. This analogue serves to preserve and expand the knowledge (information) for the original, for the design of the original, its restructuring or its management.

The refore the complex model of social adaptation of the discharged from military service servicemen and the members of their families, is a part precisely of the socio-pedagogical practice that can and should be studied, designed, probated and implemented in this reality, with new features, properties and characteristics.

The complex model is constructed in such a way that it complies with all the basic requirements of the technology of modeling: to be an objective reflection of the modeled object, to be able to replace it in certain respects; to provide for experimental verification of the achieved results, which to be interpreted at individual stages through the same substantive terms of the military-social work and social pedagogy.

Since scientifically, social adaptation is understood as a system, as a process and as an activity, its objects are the military reservists and the members of their families. At that, the model on the one hand implies inseparable unity of family members in the realization of all activities, and on the other hand - initial assignment to the whole family of a status of a subject with its own social adaptation to civil life.

Taking into account the fact that the model is a simplified, "collapsed” model of a real event, a phenomenon, a process, the model for social adaptation of servicemen is viewed in two plans: structural-componential (organization-subjects) and structural-functional (basic functions, seen as areas of social adaptation). Moreover, the model plays a role of a method of knowledge of social practice, as well as a method for the restructuring the social practice in the field of social adaptation of the discharged from military service servicemen and the members of their families. The model is , a mentally represented or materially realizable system", which, portraying or reproducing the object of study is able to replace it so that its study can give us new information about the object.

The structural-componential composition of the model implies merging all units involved in the process of social adaptation (as means of their financial support) and means for development of entrepreneurial activity. Along with this, other organizations also become structural elements of the model for social adaptation educational; research; social; women's associations; territorial bodies local government, etc.. Moreover, preference is given to those organizations that are created by the discharged from military service servicemen and the members of their families, or those in which this category of the population is significantly represented.

The structural-functional composition of the model implies the unification of the main directions of social adaptation of servicemen, discharged from military service, and the members of their families, but also selecting among the main directions those which are based on the model, the ones most important for its change, the ones most stable in the real conditions of life activity in the different conditions of the social sphere.

Basis of the social adaptation of servicemen become: professional guidance; psychological rehabilitation (psychological assistance); socio-psychological and socio-pedagogical adaptation, attracting the discharged 
from military service servicemen and the members of their families, to small businesses, establishment of structures for support of small businesses, job placement, and if necessary - their professional retraining (requalification).

The content of the model of social adaptation of the servicemen, passing in the reserve, and the members of their families, determines its bringing under the standard, because it is used for studying and change of the normative properties of the object which is really existing in the practice of military-social work. In the experimental work the model of social adaptation of the servicemen, passing in the reserve and the members of their families, isalso used as a substitute model, because with its help, research and development work is carried out.

In accordance with the requirements of the technology of socio-pedagogical modeling, the development of the integrated model of social adaptation of the discharged from military service servicemen and the members of their families, is performed by a continuous change of three interconnected stages.

In the first stage (the stage of forming the model) is performed the separation of the main components (of the structure and the function) in the activity on social adaptation of servicemen (in its content, directions, forms and methods), which are then subjected to modifications in the model - research and development restructuring.

The second stage (the stage of restructuring of the model) is related to the change of some of its properties (of the structure and the function) with regard to the conditions of studied and presented above social background. The time of the this stage of the study spans over three years, and the content of the activity at this stage comprises the contents of the experimental work.

The third stage (the stage of transferring the results onto the object), is a set of recommendations, practical measures and proposals, prepared and partially realized in the process of experimental work on forming the complex model of social adaptation of the servicemen, passing in the reserve. At this stage also carried out is verification of the authenticity, validity, effectiveness and viability of the resulting model.

The process of development, approbation and realization of the model for social adaptation of servicemen, discharged from military service, and the members of their families is carried out with consideration of the specific socio-pedagogical modeling.

For example, this model is not only a standard model, but also a model-substituent. As a standard model, it is used with reference to the existence of basic subsystems and types of activity on social adaptation of the discharged from military service servicemen and the members of their families, for the purpose of studying and restructuring the normative properties of this activity. As a model-substitute it is used for constructive development work on the problems of social adaptation of the servicemen, passing in the reserve and the members of their families.

Further on, recognizing that socio-pedagogical models are serving as values, goals, directions of their further development, the complex model of social adaptation of the discharged from military service servicemen is in nature twofold. In the process of its formation and approbation it is indicated that the inter-related types of activities are not always strictly fixed in their sequence.

In this connection, the developed model is on the one hand invariant, because the presented types of activities and areas of social adaptation of the discharged from military service servicemen and the members of their families, constitute its main content. On the other hand, the model is multi-variant, as the sequence of these types of activities and directions of social adaptation of the said category of the population is constructed in accordance with the social needs of each military reservist and his family. Here an individual profile of social adaptation of each individual is meant.

With the realization of the program, the main focus falls on the places of compact residence of families of servicemen of different types (structural-geographic composition of the model), located in the city limits distinct areas of residential buildings, as well as the ones located within the city without being compact.

An important conceptual aspect of modeling the social adaptation of the discharged from military service servicemen and the members of their families, are the theoretical foundations of social work, defining its priorities and content, nature and approaches, principles, methods and forms (Terziev, 2018a, pp. 228-236; Stefanov, Terziev, Banabakova, 2018b, pp. 93-102; Stefanov, Terziev, Banabakova, 2018c, pp. 111-119; Terziev, Stefanov, Banabakova, 2018d, pp. 120-131; Terziev, Stefanov, Banabakova, 2018e, pp. 132-148; Terziev, 2018f, pp. 213-227; Terziev, 2018g, pp. 237-247; Terziev, 2018h, pp. 256-265; Terziev, 2018i, pp. 266-276; Terziev, Latyshev, Georgiev, 2018j, pp. 248-255; Glushkov, Simeonov, Georgiev, 2018k, pp. 8892). 
Classification built on such foundations allows to present them in the form of a set of the most popular theories of social work, individual grounds of which lie in the theoretical justification of the complex model of social adaptation of servicemen, discharged from military service and the members of their families. It comes to the following:

- Psychological oriented theories of social work (existential, humanistic, psycho-dynamic, crisisinterventive; behavioral; permitting; bioenergetic; body-oriented; dianetic; socionic; psychosynthetic);

- Sociological theories of social work (system-wide, socio-ecological, radical, Marxist);

- Complex (inter-disciplinary) theories of social work (vital-oriented; cognitive; conflictoriented; sociopedagogical; socio-cultural).

Each of these theories has its content, target orientation, methods of knowledge and changes in social practice. Development and implementation of the model for social adaptation of discharged servicemen and the members of their families implies reference to the provisions of these theories, not by the unanimous application of only one of them, but by the complex utilization of the provisions of each theory, which ensures the effective functioning of this model.

One of the leading conceptual ideas of the complex model reflecting socio-pedagogical values is presented by the drawn by us principles of social adaptation of the discharged from military service servicemen and the members of their families.

The principle of personal-social-action approach implies:

- Placement in the center of the activity on social adaptation of the particular individual - the servicemen, as a member of the family, within the family and with the family;

- Taking into account the whole range of needs of the serviceman (and every member of his family) working with them on their social adaptation: individually-physiological, value-material, socio-personal, professionally-active, universal, culturological, educational, etc.;

- Organization of the work on their social adaptation by its orientation primarily to the specific (regional, municipal, city, district, etc.) socium, in view of the specifics of the surrounding social environment;

- Active nature of participation in the social adaptation of the servicemen, passing in the reserve and the members of their families themselves, their re-orientation from passive to activetransforming activity in the new social environment of their residence.

Full consideration and satisfaction of the whole range of human needs is possible only in the presence of support in the family, so the core of all processes of social adaptation constitutes the work with the family. At the end of the day, the family cannot be just a user of a particular set of social services, it should also be their provider. It is the active participation of the members of the family in solving its own problems, together with the particular specialist from the Social Work office, who promote the active development of the individual, and at the same time both the civil and the military socium, and the mechanisms of their interaction.

The principle of integration in the social adaptation of the servicemen, discharged from military service and the members of their families, implies:

- Bringing together the various vertical (organizational) structures for social work (sociopedagogical, medical, economic, psychological, cultural, educational, social protection, etc.) to attract servicemen, discharged from military service, and the members of their families, in socioproductive activities directly in their new socium;

- Integration of inter-institutional and differentiated (specialized) services for social work in complex social services (centers) in the specific areas in the settlements;

- Ensuring amulti-profile nature and complementarity in the work on social adaptation of the servicemen, passing in the reserve, and the members of their families in the places of their residence in the new living environment;

- Formation of a structure for work on social adaptation of the discharged from military service servicemen as a service of medical-psychological-pedagogical nature, helping them to solve the main social problems at the level of the particular individual in relation to his transition from military to civil socium.

The principle of involving pedagogics in the work on social adaptation of the servicemen, passing in the 
reserve and the members of their families, provides for the use of socio-pedagogical theory in its capacity of a complex basis, as a basis for the organization of all the work. It implies:

- Preventive nature of social adaptation, which begins before the discharge of servicemen from military service and their transformation into reservists, with its focus being not so much on solving the sharp social problem of their families (without giving up this type of activity), as on diagnostics-forecasts and prophylacticpreventive activity immediately in the new environment of residence, in the particular civil socium;

- Introduction of the profession „social pedagogue” in the Bulgarian army and the respective positions in the social infrastructure of military units and military educational institutions, where the members of servicemen's families and the military reservists, live; one of its functions must be timely work on preparing the servicemen and their families for the transition from military to civil socium;

- Organizing the impacts on all aspects of the life and activity of servicemen, the ones discharged from military service, and the members of their families; uniting the efforts of preschool and school, family, military, industrial pedagogy and the pedagogy of communication, preventive pedagogy, pedagogy of creativity and leisure, in an unified military-social pedagogy, in the interests of social education of servicemen and the members of their families, their sociopedagogical escort from the moment of starting their military service until their successful integration into the civil society, after its completion.

The principle of socio-cultural orientation of social adaptation of the discharged from military service servicemen and the members of their families, implies:

- Use of the term "culture of the socium”, understood as an objective and a criterion for assessing the level of development of human habitation environment, including servicemen, discharged from military service, and the members of their families, in their specific places of residence; using this concept as a qualitative characteristic of the way to solve the tasks of their social adaptation and satisfying the needs of this adaptation's objects; its application as an indicator of the development of one or another social environment;

- Orientation of the work on social adaptation to the formation of a multi-variant model of socio-cultural behavior of the servicemen, passing in the reserve and the members of their families, in both the military and civil socium. The multi-variant model of socio-cultural behavior implies the formation of a culture of soldier's labor, culture of social interaction and communication, culture of family life, lifestyle and behavior, culture of the common military etiquette, culture of speech and appearance of the military man (even the military reservist) culture of his feelings, etc.

- On the other hand, the work on social adaptation of the servicemen, passing in the reserve and the members of their families, and the social work with them in the new for them civil socium, are oriented towards the formation of a multi-variant model of culture in various spheres of social consciousness (legal, aesthetic, environmental, economic, political, educational, moral, artistic, physical, and so on);

- Using the potential of cultural and educational activities, of cultural institutions of civil socium, as a fundamental tool for social adaptation of this category of the population.

- The principle of scientific validity of the social adaptation of the discharged from military service servicemen and the members of their families, implies:

- Study of domestic and foreign experience to determine the content, organization and methodology of this work, summarizing, analyzing and taking into account lessons learned from this experience in organizing this type of activity in civil socium; appropriate use of the experience of social work across the society and the different categories of the population; preparation of summarized methodological recommendations of the experts involved in working with military reservists and the members of their families;

- Organization of permanent research studies in the area of methodology, theory, methods and practice of social adaptation of this category of the population with a view to the specifics of its development as an aggregate of various types of activity;

- Training of social pedagogues and social workers with a view to the best Bulgarian and foreign practice on the basis of specially organized scientific studies of this practice.

- The process of social adaptation is carried out in two main directions: on the one hand, indicated are the specific for the military reservists and the members of their families, directions and technologies of social adaptation, and on the other hand, are sought the common to all categories of the population changing their socium or profession, directions and technologies.

This group includes technologies of: planning, realization of the goals and value orientations, ensuring 
feedback and information provision of the educational and transforming activity on social adaptation of former military personnel and the members of their families. Collectively they represent a closed-loop of the technological process of the work on social adaptation of each category of the population in a status of transition from one typeof life conditions to another.

Specific technologies of the social adaptation of the discharged from military service servicemen and the members of their families, also include the technologies for their professional orientation; rehabilitation; socio-psychological rehabilitation; socio-pedagogical adaptation; attraction to small businesses; support of small businesses; job placement; conversion and monitoring.

General and specific technologies in their entirety and interconnection represent the technological and transforming potential of the complex model of social adaptation of the military reservists and the members of their families.

An important issue is the potential of the complex model of social adaptation of the discharged from military service servicemen and the members of their families, as a qualitative and multivariant technological model for social adaptation of individuals changing their socium, profession, way of life. In particular, probated are the possibilities for implementation of the model with migrants from underdeveloped regions of the country; with those released from places of imprisonment; the unemployed, etc.

Thus the developed and piloted model for social adaptation of military reservists and the members of their families is in its nature complex, in its content - socio-pedagogical, in its degree of practical relevance technological, in its level of interaction- inter-institutional. Such an approach to the development and implementation of the model within the Program for social adaptation of military reservists and the members of their families, seriously differs from all preceding models, projects, concepts and programs, realized for the purpose of military-social work with the discharged from military service servicemen and the members of their families (Banabakova, Georgiev, 2017a, pp. 37-47; Banabakova, Georgiev, 2018I, pp. 462-467; Terziev, 2017b, pp.517-528; Terziev, 2017c; Hristov, 2018m, pp. 277-282; Terziev, Nichev, 2017d, p.152; Terziev, Nichev, 2017e, pp.846-850; Terziev, Nichev, 2017f, p.164; Terziev, Nichev, 2017g, pp.915-919; Terziev, Madanski, Georgiev, 2017h, pp.743-747; Terziev, Madanski, Georgiev, 2017i, pp.748-753; Terziev, Nichev, Stoyanov, Georgiev, 2017j, pp.690-694; Terziev, Latyshev, Georgiev, 2017k, pp.754-772; Terziev, Nikolay, Bogdanov, 2017I, pp.671-677; Terziev, Madanski, Kanev, 2017m, pp.1331-1346; Terziev, Madanski, Kanev, 2017n, pp.1355-1372; Terziev, Madanski, Kanev, 2017o, pp.1380-1393; Terziev, Madanski, Kanev, 2017p, pp.396-415; Terziev, 2017q, pp.641-653; Terziev, Nichev, 2017r, pp.627-630; Terziev, Madanski, Kanev, 2017s, pp.575-594; Terziev, 2017t, pp.22-28; Terziev, Nichev, 2017u, pp.646658; Terziev, Nichev, 2017v, pp.659-670; Terziev, Madanski, 2017w, pp.610-625; Terziev, Madanski, 2017x, pp.917-937).

\section{CONCLUSION}

In summary, the issue with the changes to the structure of one or another sphere in the state and society, in one or another sector of a particular sphere, pertains to the problems of the dynamic development of the country and is determined by their dependence on the economy, the level of development of science and technology, etc. On the other hand, the qualitative-quantitative characteristics of one or another sphere and its sectors, are determined by external factors: international political and economic relations, degree of threats to national security, and so on.

The downsizing and restructuring of the Bulgarian army is determined precisely by these processes, therefore it has an objective character. However, implementation of this process, its organization and management, have a subjective character, determined by the human factor.

These and other reasons became the basis for the development of a comprehensive model of the social adaptation of the discharged from military service servicemen, acceptable to those servicemen who are integrated into civil socium, precisely in the places of their residence. At that, leading becomes the approach to change from a position of provision of targeted support for a certain group of the population, to an actively transforming position: inclusion of military reservists and the members of their families in active socioeconomic activity in the places of their residence, in the institutions of the civil socium, i.e. fully accounting the potential of this group of the population.

This model is suitable for use and approbation of its main elements in the whole country, in different conditions, in working with different groups of servicemen, discharged from military service. Thus, the frequently discussed in the public domain issue - is the social adaptation of the servicemen, discharged from military service and the members of their families a myth or reality - becomes soluble, in support of the reality and effectiveness of the studied by us topic, through the applicability of the complex approach, the 
IJASOS- International E-Journal of Advances in Social Sciences, Vol. V, Issue 13, April 2019

interaction between institutions and direct interest on the part of the government and the business.

\section{REFERENCE LIST}

Terziev, Venelin. (2018a). Building a model of social and pshychological adaptation. // ADVED 2018-4th International Conference on Advances in Education and Social Sciences Abstracts \& Proceedings, 1517 October 2018- Istanbul, Turkey, International Organization Center of Academic Research, www.ocerints.org, Istanbul, Turkey, 2018, pp. 228-236, ISBN: 978-605-82433-4-7.

Stefanov, S., Terziev, V., Banabakova, V. (2018b). The undertsanding of security in the postmodern society. // ADVED 2018- 4th International Conference on Advances in Education and Social Sciences Abstracts \& Proceedings, 15-17 October 2018- Istanbul, Turkey, International Organization Center of Academic Research, www.ocerints.org, Istanbul, Turkey, 2018, pp. 93-102, ISBN: 978-605-82433-4-7.

Stefanov, S., Terziev, V., Banabakova, V. (2018c). Levels of security and postmodern society. // ADVED 2018- 4th International Conference on Advances in Education and Social Sciences Abstracts \& Proceedings, 15-17 October 2018- Istanbul, Turkey, International Organization Center of Academic Research, www.ocerints.org, Istanbul, Turkey, 2018, pp. 111-119, ISBN: 978-605-82433-4-7.

Terziev, V., Stefanov, S., Banabakova, V. (2018d). Implementattion of the common european security and defence policy in the context of its military aspect. // ADVED 2018- 4th International Conference on Advances in Education and Social Sciences Abstracts \& Proceedings, 15-17 October 2018- Istanbul, Turkey, International Organization Center of Academic Research, www.ocerints.org, Istanbul, Turkey, 2018, pp. 120-131, ISBN: 978-605-82433-4-7.

Terziev, V., Stefanov, S., Banabakova, V. (2018e). Common european security and defence policy. // ADVED 2018- 4th International Conference on Advances in Education and Social Sciences Abstracts \& Proceedings, 15-17 October 2018- Istanbul, Turkey, International Organization Center of Academic Research, www.ocerints.org, Istanbul, Turkey, 2018, pp. 132-148, ISBN: 978-605-82433-4-7.

Terziev, Venelin. (2018f). Bulgarian experience in the development of social adaptation of military personnel, discharged from military service and their families. // ADVED 2018- 4th International Conference on Advances in Education and Social Sciences Abstracts \& Proceedings, 15-17 October 2018- Istanbul, Turkey, International Organization Center of Academic Research, www.ocerints.org, Istanbul, Turkey, 2018, pp. 213-227, ISBN: 978-605-82433-4-7.

Terziev, Venelin. (2018g). Opportunities of aplication of a competence-based approach in social adaptation of militaries discharged of service. // ADVED 2018- 4th International Conference on Advances in Education and Social Sciences Abstracts \& Proceedings, 15-17 October 2018- Istanbul, Turkey, International Organization Center of Academic Research, www.ocerints.org, Istanbul, Turkey, 2018, pp. 237-247, ISBN: 978-605-82433-4-7.

Terziev, Venelin. (2018h). Possible aspects of occupational and psychological adaptation of the military, discharged from military service and their families to a new activity life cycle. // ADVED 2018- 4th International Conference on Advances in Education and Social Sciences Abstracts \& Proceedings, 1517 October 2018- Istanbul, Turkey, International Organization Center of Academic Research, www.ocerints.org, Istanbul, Turkey, 2018, pp. 256-265, ISBN: 978-605-82433-4-7.

Terziev, Venelin. (2018i). Realities of implementing the social adaptation process of military personnel, discharged form service in Bulgaria. // ADVED 2018- 4th International Conference on Advances in Education and Social Sciences Abstracts \& Proceedings, 15-17 October 2018- Istanbul, Turkey, International Organization Center of Academic Research, www.ocerints.org, Istanbul, Turkey, 2018, pp. 266-276, ISBN: 978-605-82433-4-7.

Terziev, V., Latyshev, O., Georgiev, M. (2018j). The warehousing as an element of army logistics system in conditions of arctics (from experience of bulgarianrussian cooperation). // ADVED 2018- 4th International Conference on Advances in Education and Social Sciences Abstracts \& Proceedings, 1517 October 2018- Istanbul, Turkey, International Organization Center of Academic Research, www.ocerints.org, Istanbul, Turkey, 2018, pp. 248-255, ISBN: 978-605-82433-4-7.

Glushkov, P., Simeonov, S., Georgiev, M. (2018k). Method of determination of the diurnal energy 
consumption of the cadets from the Vasil Levski National Military university. ADVED 2018- 4th International Conference on Advances in Education and Social Sciences Abstracts \& Proceedings, 1517 October 2018- Istanbul, Turkey, International Organization Center of Academic Research, www.ocerints.org, Istanbul, Turkey, 2018, pp. 88-92, ISBN: 978-605-82433-4-7.

Banabakova, V., Georgiev, M. (2017a). Problems and perspectives in Military professional education and realization of cadets in Bulgaria. // Journal of Innovations and Sustainability, Innovations and Sustainability Academy. 3, 2017, N 4, pp. 37-47, ISSN 2367-8127 (CD-ROM), ISSN 2367-8151 (online).

Banabakova, V., Georgiev, M. (2018I). Military professional forming of the cadets at Vasil Levski National Military University. // Proceedings of INTCESS2018- 5th International Conference on Education and Social Sciences 5-7 February 2018- Istanbul, Turkey, International Organization Center of Academic Research, www.ocerints.org, Istanbul, Turkey, 2018, pp. 462-467, ISBN : 978-605-82433-2-3.

Terziev, Venelin. (2017b). Opportunities and trends in the development and the improvement processes in the Bulgarian military educational system. // 3rd Central \& Eastern European LUMEN International Conference, New Approaches in Social and Humanistic Sciences NASHS 2017, Chisinau, Republic of Moldova, June 8-10, 2017, 2018, pp.517-528, ISSN (print): 2601 - 2510, ISSN (on-line): 2601 2529, ISSN-L: 2601 - 2510, ISBN: 978-1-910129-15-9.

Terziev, Venelin. (2017c). Opportunities for improving the efficiencyof the socialadaptation of servicemen discharged from military service in Bulgaria. // Catalogue of the scientific, educational and methodical literature presented by authors at the I-XXXIV All-Russian book exhibitions held by Academy of Natural History, Exposition on the Frankfurter Buchmesse 2017, XXVII, Moskow, Academy of Natural History, 2017.

Hristov, Neno. (2018m). European intervention initiative vs common European army. ADVED 2018- 4th International Conference on Advances in Education and Social Sciences Abstracts \& Proceedings, 1517 October 2018- Istanbul, Turkey, International Organization Center of Academic Research, www.ocerints.org, Istanbul, Turkey, 2018, pp. 277-282, ISBN: 978-605-82433-4-7.

Terziev, V., Nichev, N. (2017d). Research on the management skills and abilities acquired in the military education system. // CBU International Conference Book of Abstracts March 22-24, Prague, Czech Republic, Innovations in Science and Education, 2017, ISBN 978-80-88042-09-9, p.152.

Terziev, V., Nichev, N. (2017e). Research on the management skills and abilities acquired in the military education system. // CBU International Conference Proceedings 2017, March 22-24, Prague, Czech Republic, Innovations in Science and Education, 2017, SSN 1805-997X (Print), ISBN 978-80-8804207-5 (Print edition), pp.846-850.

Terziev, V., Nichev, N. (2017f). Developing the readiness for the organizational activity of the cadets. // CBU International Conference Book of Abstracts March 22-24, Prague, Czech Republic, Innovations in Science and Education, ISBN 978-80-88042-09-9, p.164.

Terziev, V., Nichev, N. (2017g). Developing the readiness for the organizational activity of the cadets. // CBU International Conference Proceedings 2017, March 22-24, Prague, Czech Republic, Innovations in Science and Education, 2017, SSN 1805-997X (Print), ISBN 978-80-88042-07-5 (Print edition), pp.915-919.

Terziev, V., Madanski, V., Georgiev, M. (2017h). Offset implementation impact on technology transfer in Bulgaria. // Proceedings of ADVED 2017- 3rd International Conference on Advances in Education and Social Sciences 9-11 October 2017- Istanbul, Turkey, 2017, ISBN: 978-605-82433-0-9, pp.743-747.

Terziev, V., Madanski, V., Georgiev, M. (2017i). Offset as an economic operation and a trade practice. // Proceedings of ADVED 2017- 3rd International Conference on Advances in Education and Social Sciences 9-11 October 2017- Istanbul, Turkey, 2017, ISBN: 978-605-82433-0-9, pp.748-753.

Terziev, V., Nichev, N., Stoyanov, E., Georgiev, M. (2017j). A general principle of the development process of balanced scorecards as an instrument of control. // Proceedings of ADVED 2017- 3rd International Conference on Advances in Education and Social Sciences 9-11 October 2017- Istanbul, Turkey, 2017, ISBN: 978-605-82433-0-9, pp.690-694.

Terziev, V., Latyshev, O., Georgiev, M. (2017k). Building competencies for social work through continuing vocational training. // Proceedings of ADVED 2017- 3rd International Conference on Advances in Education and Social Sciences 9-11 October 2017- Istanbul, Turkey, 2017, ISBN: 978-605-82433-0-9, 
pp.754-772.

Terziev, V., Nikolay, N., Bogdanov, P. (2017I). Comparative analysis of the formation of military professional skills in the cadets to be trained in logistics specializations. // Proceedings of ADVED 2017- 3rd International Conference on Advances in Education and Social Sciences 9-11 October 2017- Istanbul, Turkey, 2017, ISBN: 978-605-82433-0-9, pp.671-677.

Terziev, V., Madanski, V. Kanev, D. (2017m). Entry opportunities in the Bulgarian military-educational system. // Sport, Education and Society, Taylor \& Francis, 22, 2017, N 8(2), Source Normalized Impact per Paper (SNIP): 1.459 SCImago Journal Rank (SJR): 1.005 Impact factor: 1.269 Ranking: 60/230 (Education \& Educational Research), 20/44 (Hospitality, Leisure, Sport and Tourism), 51/82 (Sport Sciences), Print ISSN: 1357-3322 Online ISSN: 1470-1243, pp.1331-1346.

Terziev, V., Madanski, V., Kanev, D. (2017n). Condition and capabilities of the military-educational system of the Republic of Bulgaria. // Sport, Education and Society, Taylor \& Francis, 22, 2017, N 8(2), Source Normalized Impact per Paper (SNIP): 1.459 SCImago Journal Rank (SJR): 1.005 Impact factor: 1.269 Ranking: 60/230 (Education \& Educational Research), 20/44 (Hospitality, Leisure, Sport and Tourism), 51/82 (Sport Sciences), Print ISSN: 1357-3322 Online ISSN: 1470-1243, pp.1355-1372.

Terziev, V., Madanski, V., Kanev, D. (20170). Directions for improvement of the military-educational system and its contribution for strengthening national security and the defence of the country. // Sport, Education and Society, Taylor \& Francis, 22, 2017, N 8(2), Source Normalized Impact per Paper (SNIP): 1.459 SCImago Journal Rank (SJR): 1.005 Impact factor: 1.269 Ranking: 60/230 (Education \& Educational Research), 20/44 (Hospitality, Leisure, Sport and Tourism), 51/82 (Sport Sciences), Print ISSN: 1357-3322 Online ISSN: 1470-1243, pp.1380-1393.

Terziev, V., Madanski, V., Kanev, D. (2017p). Entry opportunities in the bulgarian military-educational system and ensuring of civil rights. // IJAEDU- International E-Journal of Advances in Education, 3, 2017, N 8 , e-ISSN:2411-1821, pp.396-415.

Terziev, Venelin. (2017q). The needs of continuing vocational training of social work specialists providing social services. // Proceedings of SOCIOINT 2017- 4th International Conference on Education, Social Sciences and Humanities 10-12 July 2017- Dubai, UAE, 2017, ISBN: 978-605-82433-1-6, pp.641-653.

Terziev, V., Nichev, N. (2017r). Analysis of the environment for military educational system functioning and its impact on the preparation of cadets for military professional activities in the republic of Bulgaria. // Proceedings of SOCIOINT 2017- 4th International Conference on Education, Social Sciences and Humanities 10-12 July 2017- Dubai, UAE, 2017, ISBN: 978-605-82433-1-6, pp.627-630.

Terziev, V., Madanski, V., Kanev, D. (2017s). Entry opportunities in the bulgarian military-educational system and ensuring of civil rights. // Proceedings of SOCIOINT 2017- 4th International Conference on Education, Social Sciences and Humanities 10-12 July 2017- Dubai, UAE, 2017, ISBN: 978-60582433-1-6, pp.575-594.

Terziev, Venelin. (2017t). National security of the republic of Bulgaria. // International Journal of Management and Applied Science, 3, 2017, N 4, ISSN: 2394-7926, pp.22-28.

Terziev, V., Nichev, N. (2017u). Research of the value orientation and structural peculiarities of management activitiesofcadets in the course of military professional training. // Proceedings of the VII International Academic Congress „Fundamental and Applied Studies in EU and CIS Countries” (United Kingdom, Cambridge, England, 26-28 February 2017), Cambridge University Press, 7, 2017, ISBN: 978-0-87583597-4, pp.646-658, Source Normalized Impact per Paper (SNIP): 5.192 SCImago Journal Rank (SJR): 5.186 Impact factor: 7.549 .

Terziev, V., Nichev, N. (2017v). Research of the motivation for management activities of cadets in the course of their military professional training. // Proceedings of the VII International Academic Congress „Fundamental and Applied Studies in EU and CIS Countries” (United Kingdom, Cambridge, England, 26-28 February 2017), Cambridge University Press, 7, 2017, ISBN: 978-0-875-83597-4, pp.659-670, Source Normalized Impact per Paper (SNIP): 5.192 SCImago Journal Rank (SJR): 5.186 Impact factor: 7.549 .

Terziev, V., Madanski, V. (2017w). Guidelines for development of military education system in Bulgaria. // Proceedings of the VII International Academic Congress "Fundamental and Applied Studies in EU and CIS Countries" (United Kingdom, Cambridge, England, 26-28 February 2017), Cambridge University Press, ISBN: 978-0-875-83597-4, 7, 2017, pp.610-625, Source Normalized Impact per Paper (SNIP): 5.192 SCImago Journal Rank (SJR): 5.186 Impact factor: 7.549 . 
Terziev, V., Madanski, V. (2017x). Development of military education system in Bulgaria. // American Journal of Education, The University of Chicago Press, 2017, 123, 2017, N 4 (2), ISSN: 0195-6744, pp.917937, Source Normalized Impact per Paper (SNIP): 1.653, SCImago Journal Rank (SJR): 2.243. 